\title{
Pengukuran Sistem Informasi Menggunakan Metode Function Point (FP) pada SIAKAD Universitas XYZ
}

\author{
Elok Tiara Cahya Septi, Firdayatul Dewi Sartika, Renny Sari Dewi * \\ Fakultas Teknologi Industri dan Kreatif, Sistem Informasi, Universitas Internasional Semen Indonesia, Gresik, Indonesia \\ Email: ${ }^{1}$ eloktiara28@gmail.com, ${ }^{2}$ firdaaayatu105@gmail.com, ${ }^{3,}$ "renny.dewi@uisi.ac.id \\ Email Penulis Korespondensi renny.dewi@uisi.ac.id
}

Submitted 07-01-2020; Accepted 04-02-2020; Published 15-02-2020

\begin{abstract}
Abstrak
Perhitungan biaya perangkat lunak ialah suatu aktivitas yang dilakukan untuk mengetahui nilai sebuah perangkat lunak dengan menggunakan pendekatan kuantitatif. Melihat adanya berbagai macam metode pengukuran dan masih belum ada standar dalam melakukan penilaian terhadap perangkat lunak membuat proses pengukuran ini diabaikan, meskipun proses ini memiliki peran yang strategis dalam pengembangan perangkat lunak. Penelitian ini bermaksud untuk menghitung ukuran usaha pengembangan perangkat lunak sistem informasi akademik dengan metode Function Point (FP). Tahapan yang dilakukan adalah (1) menghitung besaran function points, (2) mengkalkulasi usaha pengemngan perangkat lunak, dan (3) mendistribusikan besaran effort ke masing-masing aktivitas. Hasil penelitian ini adalah effort pengembangan sistem informasi akademik adalah 1,460 Orang/jam dan besaran nominalnya adalah IDR 177,917,997.
\end{abstract}

Kata Kunci: Sistem Akademik, Estimasi Biaya, Function Point, Estimasi Perangkat Lunak

Abstract

Software cost calculation is an activity carried out to determine the value of a software using a quantitative approach. Seeing that there are various measurement methods and there are still no standards in assessing software, this measurement process is ignored, even though this process has a strategic role in software development. This research intends to calculate the size of the business of developing academic information system software with the Function Point (FP) method. The steps taken are (1) calculating the amount of function points, (2) calculating the software development effort, and (3) distributing the amount of effort to each activity. The results of this study are efforts to develop an academic information system is 1,460 people / hour and the nominal amount is IDR 177,917,997.

Keywords: Academic Systems, Cost Estimates, Function Points, Software Estimates

\section{PENDAHULUAN}

Semakin berkembang dan luasnya penggunaan komputer memicu banyaknya perangkat lunak yang turut tumbuh dan berkembang dalam jumlah dan kegunaannya. Kebanyakan proyek perangkat lunak mengalami kegagalan dikarenakan estimasi waktu, sumber daya manusia dan perkiraan biaya. Kebanyakan permasalahan pada proyek perangkat lunak tidaklah nyata. [1]. Pengukuran volume software telah menjadi suatu perbincangan hangat di kalangan pengembang dan pebisnis software. Bagi pengembang, mengukur volume dari software bermanfaat untuk merencanakan sumber daya, biaya dan durasi yang diperlukan untuk membangun software. Selain itu, pengembang juga dapat mengevaluasi kualitas produk dengan cara membandingkan

Volume sistem dengan banyaknya error (error-count) dalam software yang dikerjakan [2]. Ada beberapa metode estimasi upaya pengembangan perangkat lunak yang terkenal, yaitu logika fuzzy cara untuk memetakan suatu ruang input kedalam suatu ruang output, use case points (ucp) oleh [3]. Penelitian ini bertujuan menjelaskan pembagian lingkup kerja menggunakan metode function point untuk melakukan estimasi biaya. Metode function point diperkenalkan pertama kali oleh allan j. Albrecht pada tahun 1979, lalu perbaikan metode ini dilakukan pada tahun 1984 [4]. Sejak berdirinya international function point user group (ifpug) pada tahun 1986, menerbitkan beberapa versi dari function point counting practies manual. Pada metode function point, dapat digunakan untuk estimasi upaya penentuan jadwal, biaya dan jumlah pegawai dalam sebuah proyek pengembangan perangkat lunak. Karena salah satu penentuan keberhasilan pengerjaan sebuah proyek adalah adanya estimasi biaya dan estimasi effort suatu proyek. Dalam melakukan perhitungan function point pada proyek yang pernah dikerjakan sebelumnya, akan memudahkan pengembang dalam memprediksi penjadwalan dan biaya pada proyek serupa sehingga meminimalisir upaya dalam pengumpulan data pada skala besar. Penelitian juga dilakukan untuk meningkatkan akurasi estimasi dengan pendekatan sistem cerdas logika fuzzy [5] sehingga hasil yang didapat menjadi lebih baik. Jumlah total fp tergantung pada perhitungan yang berbeda dalam hal format atau pengolahan logika jenis. Berikut 5 jenis komponen tersebut yang terdiri dari 2 data functions dan 3 transaction types: (1). Internal logical file (ilf), merupakan logika data yang disimpan dan di maintained pada aplikasi boundary. (2). External interface file (eif), merupakan pengelompokan logika data yang berada di luar aplikasi tetapi menyediakan data yang mungkin dapat digunakan pada aplikasi. Eif sama dengan ilf hanya saja ilf yang berada pada aplikasi lain disebut eif. (3). External inputs (ei), merupakan proses data ei atau kontrol informasi yang datang dari luar application boundary. Ei dapat berupa aktifitas unit terkecil dari sebuah aplikasi. Pada implementasi ei berupa field-field pada aplikasi. (4). External outputs (eo), merupakan proses dasar dimana data melintasi boundary dari dalam aplikasi ke luar aplikasi. Eo dapat memperbaharui ilf. Pada implementasi eo bisa berupa laporan yang bisa dicetak. (5) external inquiry (eq), merupakan sebuah proses dasar yang terdiri dari gabungan inputoutput yang menghasilkan data kembalian (retrieve) atau data yang bisa di-view. Metode function point analysis telah terbukti sebagai metode yang dapat diandalkan untuk mengukur ukuran perangkat lunak komputer. Selain mengukur output, 
function point analysis sangat berguna dalam memperkirakan proyek, mengelola perubahan lingkup, mengukur produktivitas, dan mengkomunikasikan persyaratan fungsional [6].

\section{METODE PENELITIAN}

\subsection{Studi Lapangan}

Metode penelitian dimulai dari studi lapangan yang dilakukan dengan mengamati masalah masalah aktual dalam proyekproyek pengembangan perangkat lunak (software) yang ditujukan pada SIAKAD di Universitas XYZ. Dengan mengumpulkan data-data maupun informasi yang dibutuhkan untuk melakukan penelitian dari sistem perangkat lunak tersebut

\subsection{Pengumpulan Data Dan Kebutuhan Penelitian}

Pengumpulan data dilakukan dengan menggunakan wawancara untuk mendapatkan data kualitatif berupa informasi terkait kebutuhan kebutuhan fungsionalitas sistem informasi serta dilakukan dengan mengamati masalah masalah pada proyek pengembangan perangkat lunak (Software) pada SIAKAD yang telah dilakukan sebelumnya. Pada tahapan ini, dilakukan juga studi literatur dengan membaca jurnal penelitian terkait dengan metode Function Point yang dibutuhkan dalam pengembangan aplikasi. Serta dilakukan pengumpulan dar teori-teori maupun informasi guna mendukung penelitian yang sumbernya dari buku, jurnal penelitian dan internet.

\subsection{Penelitian Sebelumnya}

Pada hasil penelitian sebelumnya ini telah dilakukan terlebih dahulu serta dikelompokkan berdasarkan objek penelitiannya.

\section{a. Estimasi Biaya}

Estimasi biaya adalah proses memprediksi effort yang diperlukan untuk mengembangkan sebuah perangkat lunak. Estimasi biaya meliputi satu atau lebih dari 1) Effort, 2) project duration, 3) cost. Pada estimasi biaya ini berperan penting pada keberhasilan manajemen proyek perangkat lunak. Estimasi biaya proyek memegang peranan penting dalam penyelenggaraan proyek. [7] [8].

\section{b. Pengembangan Perangkat Lunak}

Enterprise Resource Planning (ERP) merupakan fungsi system aplikasi perangkat lunak yang dapat membantu organisasi dalam mengendalikan bisnis yang lebih baik, karena dapat mengurangi tingkat stok dan inventori, meningkatkan perputaran stok, mengurangi cycle time order, meningkatkan produktivitas, komuniksi lebih baik serta berdampak pada peningkatan benefit atau profit perusahaan. Ada beberapa tahap pengembangan perangkat lunak:

Tabel 1. Tahap Pengembangan Perangkat Lunak

\begin{tabular}{|c|c|}
\hline Tahap & Pengertian atau aktivitas \\
\hline $\begin{array}{l}\text { System / information engineering } \\
\text { (rekayasa dan pemodelan sistem) }\end{array}$ & $\begin{array}{l}\text { menyangkut pengumpulan kebutuhan (requirement gathering) pada level } \\
\text { sistem dengan sejumlah kecil analisis serta top desain. }\end{array}$ \\
\hline Analisa & $\begin{array}{l}\text { kebutuhan PL, proses requirement gathering diintensifkan dan } \\
\text { difokuskan, khususnya pada PL. Untuk memahami sifat program yang } \\
\text { dibangun, analis harus memahami domain informasi, tingkah laku, unjuk } \\
\text { kerja, dan interface yang diperlukan. Kebutuhan sistem maupun PL } \\
\text { didokumentasikan dan di review bersama user. }\end{array}$ \\
\hline Desain & $\begin{array}{l}\text { desain database, arsitektur PL, interface, dan algoritma prosedural. Proses } \\
\text { desain menerjemahkan kebutuhan ke dalam representasi PL sebelum } \\
\text { dimulai coding. }\end{array}$ \\
\hline Coding & $\begin{array}{l}\text { menerjemahkan desain ke dalam bahasa yang dimengerti mesin. } \\
\text { Logika internal PL: memastikan bahwa semua statement telah diuji (white } \\
\text { box) }\end{array}$ \\
\hline Testing & $\begin{array}{l}\text { Fungsi eksternal: mengarahkan testing untuk menemukan } \\
\text { kesalahankesalahan dan memastikan bahwa input yang diberikan akan } \\
\text { menghasilkan output sesuai yang diinginkan (black box). }\end{array}$ \\
\hline Project management & $\begin{array}{l}\text { Aktivitas dalam memanajemen rekayasa perangkat lunak, dimulai } \\
\text { sebelum aktivitas teknis di inisialisasi dan berlanjut pada keseluruhan } \\
\text { batasan, perkembangan dan pemeliharaan perangkat lunak computer } \\
\text { serta controlling dengan menggunakan resource yang ada untuk } \\
\text { membuat perangkat lunak dalam jangka waktu tertentu untuk memenuhi } \\
\text { kebutuhan. }\end{array}$ \\
\hline
\end{tabular}




\begin{tabular}{ll}
\hline Tahap & Pengertian atau aktivitas \\
\hline Configuration management & mengidentifikasi, mengorganisasi, dan mengontrol modifikasi pada \\
& software yang sedang dibangun oleh tim programming dan tujuannya \\
& untuk memaksimalkan produktivitas dengan meminimalisasi kesalahan. \\
Quality Assurance & seseorang yang bertanggung jawab terhadap perencanaan jaminan \\
& kualitas, kesalahan, penyimpanan rekaman, analisis, dan pelaporan. \\
& Jaminan kualitas perangkat lunak adalah aktivitas pelindung yang \\
& diaplikasikan pada seluruh proses perangkat lunak. Proses ini, bisa \\
& dilaksanakan oleh seorang QA Tester atau oleh seorang QA Engineer. \\
Documentation & Menulis user guide (on-line bantuan, panduan, pengguna, manual \\
& referensi, tutorial, materi, penelitian). Menulis dokumentasi system. \\
Training and support & Memberikan pelatihan atau arahan untuk menjalankan perangkat lunak \\
& yang telah dikembangkan. \\
Evaluation and testing & Perubahan atau mengevaluasi yang berkembang dan adaptasi perangkat \\
lunak dengan kondisi, situasu sebenarnya telah disampaikan oleh & \\
\hline
\end{tabular}

\section{c. Enterprise Resource Planning (ERP)}

Enterprise Resource Planning (ERP) merupakan fungsi system aplikasi perangkat lunak yang dapat membantu organisasi dalam mengendalikan bisnis yang lebih baik, karena dapat mengurangi tingkat stok dan inventori, meningkatkan perputaran stok, mengurangi cycle time order, meningkatkan produktivitas, komuniksi lebih baik serta berdampak pada peningkatan benefit atau profit perusahaan.

\section{d. Estimasi Biaya Menggunakan Function Points dalam Pengembangan Perangkat Lunak.}

Dalam penelitian sebelumnya telah dilakukan penelitian menggunakan motode function points untuk menghitung estimasi biaya perangkat lunak sistem informasi.

Tabel 2. Estimasi Biaya Menggunakan Function Points dalam Pengembangan

\begin{tabular}{|c|c|c|c|}
\hline Penulis & Judul & Hasil & Keterkaitan \\
\hline [9] & $\begin{array}{l}\text { UCPabc as an integration } \\
\text { model for software cost } \\
\text { estimation }\end{array}$ & $\begin{array}{l}\text { Tingkat akurasi model perkiraan } \\
\text { biaya menggunakan UCPabc } \\
\text { dibandingkan dengan biaya yang } \\
\text { sebenarnya memiliki sebuah } \\
\text { penyimpangan rendah } 2,16 \\
\text { persen }\end{array}$ & Estimasi biaya software \\
\hline [10] & $\begin{array}{l}\text { Software Effort } \\
\text { Estimation : A } \\
\text { Comparison Based } \\
\text { Perspective }\end{array}$ & $\begin{array}{l}\text { Membandingkan estimasi effort } \\
\text { dengan pendekatan prespektif } 4 \\
\text { metode yaitu LOC, Function } \\
\text { Points, Basic COCOMO, } \\
\text { COCOMO II }\end{array}$ & $\begin{array}{l}\text { Menggunakan estimasi } \\
\text { effort }\end{array}$ \\
\hline [11] & $\begin{array}{l}\text { Analysis of Software } \\
\text { Estimation Method: } \\
\text { Function point and Use } \\
\text { case points }\end{array}$ & $\begin{array}{l}\text { Mengkombinasi metode function } \\
\text { points dengan metode use case } \\
\text { points analysis }\end{array}$ & $\begin{array}{l}\text { Analisa software estimasi } \\
\text { menggunakan metode } \\
\text { fuction points }\end{array}$ \\
\hline [12] & $\begin{array}{l}\text { Comparative Analysis of } \\
\text { Software Cost and Effort } \\
\text { Estimation Methods: A } \\
\text { Review }\end{array}$ & $\begin{array}{l}\text { Membandingkan semua metode } \\
\text { estimasi. Hasilnya LOC dan } \\
\text { Function points memainkan } \\
\text { peran utama atau dasar metode } \\
\text { estimasi }\end{array}$ & $\begin{array}{l}\text { Metode fuction points sudah } \\
\text { dikolaborasi dengan metode } \\
\text { lain untuk menentukan } \\
\text { tingkat akurasi yang optimal }\end{array}$ \\
\hline
\end{tabular}

Dalam kajian pustaka tersebut memberikan landasan penerapan function points untuk estimasi biaya dan untuk pengembangan perangkat lunak, dalam artikel tersebut dapat dijadikan acuan bahwa metode function points untuk membiayaan perangkat lunak secara umum.

\section{e. Perkiraan Biaya Perangkat Lunak}

Perkiraan biaya dan usaha proyek merupakan suatu kegiatan pengaturan sumber daya dalam mencapai tujuan dan sasaran dari proyek, sehingga proyek dapat berjalan sesuai dengan tahapan dan target yang dikehendaki. Dalam usaha perkiraan biaya sering ditemui dua permasalahan yaitu over-estimates dan under-estimates. Untuk itu, perlu dilakukan langkah yang hati-hati dalam melakukan perkiraan biaya suatu proyek perangkat lunak sehingga dapat dicapai keberhasilan proyek yaitu tepat waktu, sesuai budget dan terpenuhinya standar kualitas produk. 


\section{f. Function Points Yang Diterapkan Pada Aplikasi}

Dalam beberapa penelitian telah dilakukan penelitian menggunakan metode function points untuk menghitung estimasi biaya untuk membangun proyek software aplikasi pada system informasi.

Tabel 3. Function Points Yang Diterapkan Pada Aplikasi.

\begin{tabular}{llll}
\hline Penulis & Judul & Hasil & Keterkaitan \\
\hline$[13]$ & A Comparative Study of & Tingkat akurasi model perkiraan & Mengapdopsi untuk \\
& Software Development Size & biaya menggunakan UCPBC & mendapat penghasilkan \\
& Estimation Method: UCPabc & dibandingkan dengan biaya yang & ketepatan model \\
& vs Function Points & sebenarnya memiliki sebuah & perkiraan biaya yang \\
& penyimpanan rendah 11,9 persen. & $\begin{array}{l}\text { memiliki sebuah } \\
\text { penyimpan rendah }\end{array}$ \\
& & & \\
\hline
\end{tabular}

\section{g. Function Points Digunakan Untuk Menghitung Suatu Proyek Games Edukasi}

Dari kajian pustaka memberikan landasan penerapan function points digunakan untuk menghitung suatu proyek games edukasi untuk mengapdosi pada penelitian ini karena sama-sama membagas tentang perangkat lunas tetapi perlu menyesuaian dan pembaruan.

Tabel 4. Function Points Digunakan Untuk Menghitung Suatu Proyek Games Edukasi

\begin{tabular}{|c|c|c|c|}
\hline Penulis & Judul & Hasil & Keterkaitan \\
\hline [14] & $\begin{array}{l}\text { Game Complexity Factor: A } \\
\text { Collaborative Study of LeBlanc } \\
\text { Taxonomy and Function Points } \\
\text { Method }\end{array}$ & $\begin{array}{l}\text { Telah modifikasi metode } \\
\text { function points dengan } \\
\text { taksinomi leblanc dengan } \\
\text { disikronisasi } 22 \text { item GCF } \\
\text { (Game Complexity Factor) }\end{array}$ & $\begin{array}{l}\text { Function points untuk } \\
\text { estimasi effort }\end{array}$ \\
\hline [15] & $\begin{array}{l}\text { Ekstraksi Faktor Kompleksitas } \\
\text { Game Menggunakan Metode } \\
\text { Function Points }\end{array}$ & $\begin{array}{l}\text { Total ekstraksi pada faktor } \\
\text { kompleksitas game (FKG) } \\
\text { terdapat } 22 \text { item, yang terdiri } \\
\text { dari } 8 \text { faktor kompleksitas } \\
\text { lingkungan (mengacu pada } \\
\text { taksonomi LeBlanc) dan } 14 \\
\text { faktor kompleksitas teknis } \\
\text { (berdasarkan metode FP). }\end{array}$ & $\begin{array}{l}\text { Function points untuk } \\
\text { estimasi effort }\end{array}$ \\
\hline [16] & $\begin{array}{l}\text { Function Points Method in Game } \\
\text { Casual Context }\end{array}$ & $\begin{array}{l}\text { Metode FP biasanya terdiri } \\
\text { dari } 3 \text { tahap utama: } \\
\text { menimbang } 5 \text { parameter FP } \\
\text { yang Tidak Disesuaikan, } \\
\text { menghitung } 14 \text { faktor } \\
\text { kompleksitas, dan menghitung } \\
\text { FP yang Disesuaikan. Survei } \\
\text { ke } 8 \text { game kasual dilakukan } \\
\text { dan nilai upaya masing-masing } \\
\text { dari mereka telah diperkirakan. } \\
\text { Jadi, kami menyimpulkan } \\
\text { bahwa FP tidak cocok untuk } \\
\text { meramalkan upaya game } \\
\text { kasual mobile. Ada } 376 \text { persen } \\
\text { penyimpangan antara estimasi } \\
\text { upaya dan upaya aktual. }\end{array}$ & $\begin{array}{l}\text { Function points untuk } \\
\text { estimasi } \text { effort }\end{array}$ \\
\hline
\end{tabular}

\subsection{Function Points}

Function Point (FP) merupakan salah satu metode kuatitatif yang banyak digunakan dalam pengukuran perangkat lunak karena memiliki set kapabilitas untuk memprediksi nilai perangkat lunak dari berbagai segi objek pengukuran. Hasil pengukuran dengan menggunakan FP dengan mempertimbangkan pembobotan Function Point diperkenalkan pertama kali oleh Allan J. Albercht pada tahun 1979 lalu perbaikan metode ini dilakukan pada tahun 1984 oleh Albercht. Sejak berdirinya International Function Point Users Group (IFPUG) pada tahun 1986, menerbitkan beberapa versi dari Funtion Point Counting Practies Manual.

Metode function points adalah sebuah metode yang melakukan pendekatan berorientasi pada fungsionalitas dan kompleksitas perangkat lunak dalam mengestimasi size perangkat lunak yang selanjutnya digunakan untuk mengestimasi effort dan estimasi biaya yang diperlukan untuk pengembangan perangkat lunak.

Tahapan-tahapan yang ada dalam menentukan function point adalah sebagai berikut : 
Langkah 1 : Menghitung crude function points (CFP). Jumlah dari komponen fungsional sistem pertama kali diidentifikasi dan dilanjutkan dengan mengevaluasi kuantitasi bobot kerumitan dari tiap komponen tersebut. Pembobotan tersebut kemudian dijumlahkan dan menjadi angka CFP.

Langkah 2 : Menghitung faktor pengubah kompleksitas relatif/relative complexity adjustment factor (RCAF) untuk proyek tersebut.

Langkah 3 : Menghitung Function Point [2] .

$$
\begin{aligned}
& F P=C F P \times(0.65+0.01 \times R C A F) \\
& F P=C F P \times(0.65+(0.01 \times R C A F)) \\
& E f f o r t=F P \times P F \\
& F P k e K L o c=F P \times 56 \\
& \text { KLockeEffort }=\frac{\text { Effort }}{18} \times 22 \times 8
\end{aligned}
$$

\section{ANALISA DAN PEMBAHASAN}

Pada dasarnya pengukuran merupakan kegiatan penentuan angka bagi suatu objek yang bertujuan untuk melakukan perkiraan dan untuk menyatakan kualitas produk. Pada pengembangan perangkat lunak, perlu adanya estimasi atau perkiraan ukuran suatu perangkat lunak yang akan dikembangkan untuk menentukan dan mengetahui berapa besar effort atau usaha yang akan dikeluarkan untuk mengembangkan perangkat lunak.

\subsection{Menghitung Nilai Crude Function Points (CFP)}

Crude Function Points (CFP) digunakan untuk menghitung bobot nilai dari komponen-komponen Function Point yang

\begin{tabular}{|c|c|c|c|c|c|c|c|}
\hline \multirow{3}{*}{ Judul Kolom } & \multicolumn{6}{|c|}{ Level Kompleksitas } & \multirow{3}{*}{ Total } \\
\hline & \multicolumn{2}{|l|}{ Mudah } & \multicolumn{2}{|c|}{ Sedang } & \multicolumn{2}{|c|}{ Kompleks } & \\
\hline & $\mathrm{J}$ & $\mathrm{P}$ & $\mathrm{J}$ & $\mathrm{P}$ & $\mathrm{J}$ & $\mathrm{P}$ & \\
\hline Tipe Input & 9 & 27 & 9 & 36 & 3 & 18 & 81 \\
\hline Tipe Output & 6 & 24 & 3 & 15 & 1 & 7 & 46 \\
\hline Tipe Query/Search/View & 0 & 0 & 0 & 0 & 2 & 12 & 12 \\
\hline Tipe File/Table/Database & 1 & 7 & 0 & 0 & 1 & 15 & 22 \\
\hline \multirow[t]{2}{*}{ Tipe Interface External } & 0 & 0 & 1 & 7 & 0 & 0 & 7 \\
\hline & & & & & & 1 (CFP) & 168 \\
\hline
\end{tabular}
dikaitkan dengan perangkat lunak yang akan dibuat.

Tabel 5. Parameter dan tingkat bobot pada CFP

\begin{tabular}{ll}
\hline Parameter Utama & \multicolumn{1}{c}{$\begin{array}{c}\text { Bobot } \\
\text { (Rendah }- \text { Sedang } \\
- \text { Kompleks) }\end{array}$} \\
\hline External Input (EI) & $3-4-6$ \\
External Output (EO) & $4-5-7$ \\
$\begin{array}{l}\text { External Inquiry (EQ) } \\
\text { Internal Logical File }\end{array}$ & $3-4-6$ \\
(ILF) & $7-10-15$ \\
$\begin{array}{l}\text { External Logical File } \\
\text { (ELF) }\end{array}$ & $5-7-10$ \\
\hline
\end{tabular}

Tabel 6. Nilai CFP sistem Informasi Akademik

\section{Keterangan :}

J (jumlah) : nilai dari tiap pembobotan pada level kompleksitas yang pada aplikasi.

$\mathrm{P}$ (poin) : hasil dari perkalian jumlah dengan bobot.

Berdasarkan perhitungan yang telah dijelaskan pada tabel 2, maka diketahui nilai Crude Functional Point (CFP) adalah 168

\subsection{Menghitung Relative Complexity Adjustive}

Tabel 7. Skala RCAF

Skala Keterangan




\begin{tabular}{ll}
\hline 1 & Insidental \\
2 & Moderat \\
3 & Rata-rata \\
4 & Signifikan \\
5 & Essential \\
\hline
\end{tabular}

Tabel 8. Tabel RCAF

\begin{tabular}{llc}
\hline No & Karakteristik & Skor \\
\hline 1 & Tingkat keandalan dan pemulihan data & 4 \\
2 & Tingkat komunikasi data & 5 \\
3 & Tingkat distribusi pemrosesan data & 2 \\
4 & Tingkat capaian kerja & 2 \\
5 & Tingkat konfigurasi lingkungan & 4 \\
6 & Tingkat kapasitas transaksi & 1 \\
7 & Tingkat efisiensi pengguna & 2 \\
8 & Tingkat pembaruan file induk & 4 \\
9 & Tingkat pembaruan real time online & 3 \\
10 & Tingkat penggunaan kembali & 2 \\
11 & Tingkat kemudahan instalasi & 3 \\
12 & Tingkat kemudahan penggunaan & 1 \\
13 & Tingkat variasi organisasi pengguna & 5 \\
14 & Tingkat kerentanan terhadap perubahan & 3 \\
\hline & TOTAL RCAF & 39 \\
\hline
\end{tabular}

Berdasarkan perhitungan nilai pada tabel 4, maka diketahui hasil dari Relative Complexity Adjustment Factor (CAF) adalah 39.

\subsection{Menghitung Function Points (FP)}

Function Point (FP) yaitu proses melakukan perhitungan untuk mendapatkan nilai Function Point dari suatu sistem yang akan dikembangkan. Untuk menghitung Function Point (FP) maka dapat menggunakan rumus (2).

Angka 0,65 dan 0,01adalah angka yang konstanta atau ketetapan yang dibuat oleh Function Point Internasional User Group (FPIUG).

Berikut perhitungan dalam menentukan nilai FP :

$$
\begin{aligned}
\mathrm{FP} & =\mathrm{CFP} \times(0,65+(0,01 \times \mathrm{RCAF})) \\
& =168 \times(0,65+(0,01 \times 39)) \\
& =174.72
\end{aligned}
$$

Maka, hasil perhitungan FP pada SIAKAD adalah 174.72

\subsection{Menghitung Effort}

Untuk melakukan perhitungan pada Effort, menggunakan rumus (3). Angka 8,2 adalah angka konstanta atau ketetapan yang dibuat oleh Function Point Internasional User Group (FPIUG).

Berikut merupakan perhitungan untuk menentukan Effort :

$$
\begin{aligned}
\text { Effort } & =\mathrm{FP} \times 8,2 \\
& =174.72 \times 8,2 \\
& =1.432,7 \text { orang/jam } \\
& =8 \mathrm{jam}
\end{aligned}
$$

Maka, hasil perhitungan Effort pada SIAKAD adalah 1.432,7 atau 8 jam.

\subsection{Menghitung FP ke KLoc (untuk Bahasa pemrograman PHP = 56)}

Untuk menghitung Kloc menggunakan rumus (4), angka 56 merupakan konstanta atau ketetapan yang dibuat oleh Function Point Internasional User Group (FPIUG).

FP ke KLoc $=$ FP $\times 56$

$$
=174.72 \times 56
$$




$$
=9.784,32
$$

Maka, hasil perhitungan KLoc pada SIAKAD adalah 9.784,32

\subsection{Menghitung KLoc ke Effort}

KLoc ke Effort $=\frac{\text { Effort }}{18} \times 22$ hari kerja $\times 8$ jam

$$
\begin{aligned}
& =\frac{1.432 .7}{18} \times 22 \times 8 \\
& =14.009 \text { orang/jam }
\end{aligned}
$$

\subsection{Menghitung Effort pada tabel pendistribusian effort ke aktifitas}

sebuah presentase tiap aktivitas yang merupakan hasil dari perhitungan final effort yang sudah diketahui dan di distribusikan ke dalam setiap aktivitas pengembangan perangkat lunak. Yang bertujuan untuk mencari estimasi biaya yang dibutuhkan dalam mengembangkan Sistem Indormasi Akademik (SIAKAD).

Misal perhitungan pada Business Analyst $=\mathbf{7 . 1 0 \%} \times \mathbf{1 4 . 0 0 9}=\mathbf{9 9 4 , 6 4}$

Angka dalam persentase (\%) didapat dari penelitian terdahulu.

\subsection{Menghitung cost pada tabel pendistribusian effort ke aktivitas}

Misal perhitungan pada Business Analyst $=994,64 \times 51.136,36=50.861 .911$

Nilai EffortPayrate/hr merupakan standart gaji oleh kelly service. Dari perhitungan maka dapat diketahui biaya keseluruhan yang harus disiapkan dalam membangun Sistem Informasi Akademik (SIAKAD) sebesar IDR 1.077.976.xxx

\subsection{Pendistribusian effort le aktivitas}

Tabel 9. Pendistribusian effort ke aktivitas

\begin{tabular}{clccrr}
\hline No & \multicolumn{1}{c}{ Activities } & \% & Effort & EffortPayrate/hr & Cost \\
\hline 1 & Business Analyst & $7.10 \%$ & 1013.74 & $17,187.50$ & $17,423,693.47$ \\
2 & Programmer & $50.00 \%$ & 7139.03 & $10,312.50$ & $73,621,240.00$ \\
3 & Tester/Software QA & $6.00 \%$ & 856.68 & $10,312.50$ & $8,834,548.80$ \\
4 & Security Consultant & $5.80 \%$ & 828.13 & $10,312.50$ & $8,540,063.84$ \\
5 & Software Development & $6.50 \%$ & 928.07 & $10,312.50$ & $9,570,761.20$ \\
6 & Project Leader & $6.90 \%$ & 985.19 & $34,375.00$ & $33,865,770.40$ \\
7 & Database Administrator & $5.20 \%$ & 742.46 & $10,312.50$ & $7,656,608.96$ \\
8 & Analyst Programmer & $6.50 \%$ & 928.07 & $10,312.50$ & $9,570,761.20$ \\
9 & Data Analyst & $6.00 \%$ & 856.68 & $10,312.50$ & $8,834,548.80$ \\
\hline & TOTAL & $\mathbf{1 0 0 \%}$ & $\mathbf{1 4 , 2 7 8}$ & & $\mathbf{1 . 0 7 7 . 9 7 6 . x x x}$ \\
\hline
\end{tabular}

\section{KESIMPULAN}

Setelah dilakukan pengukuran Sistem Informasi Akademik (SIAKAD) universitas XYZ, maka dapa diambil kesimpulan bahawa jika universitas tersebut ingin mengembangkan SIAKAD untung mendukung proses bisnisnya kurang lebih biaya yang akan dikeluarkan adalah IDR 177,917,997 atau setara dengan effort 1,460 Orang/jam.

\section{REFERENCES}

[1] M. Alnobeta, M. Saputra, and A. Herlambang, "Estimasi Biaya Perangkat Lunak Menggunakan Metode Function Point ( Studi Kasus : CV Aptikma Indonesia )," J. Pengemb. Teknol. Inf. dan Ilmu Komput. Univ. Brawijaya, vol. 2, no. 3, pp. 1072-1082, 2016.

[2] K. Kusrini and U. A. Yogyakarta, "Pengukuran Volume Software berdasarkan Kompleksitasnya dengan Metode Function Point," no. September, 2015

[3] G. Karner, "Resource estimation for objectory projects," Object. Syst. SF AB, 1993.

[4] A. J. Albrecht and J. E. Gaffney, "Software Function, Source Lines of Code, and Development Effort Prediction: A Software Science Validation," IEEE Trans. Softw. Eng., 1983.

[5] R. B. H. E. Kapita, M. Angelin, and S. R. Wicaksono, "ANALISIS KUALITAS PERANGKAT LUNAK MENGGUNAKAN METODE FUNCTION POINT ANALYSIS (STUDY KASUS: Transaksi Pembelian di eBay),” J. Inform. dan Rekayasa Perangkat Lunak, vol. 1, no. 1, 2019.

[6] Nu. Rachmat and Saparudin, "Estimasi Ukuran Perangkat Lunak Menggunakan Function Point Analysis - Studi Kasus Aplikasi Pengujian dan Pembelajaran Berbasis Web," vol. 3, no. 1, pp. 1-5, 2017.

[7] I. Soeharto, "Manajemen Proyek, penerbit Erlangga," 1997

[8] Sholiq, A. P. Subriadi, F. A. Muqtadiroh, and R. S. Dewi, "A model of owner estimate cost for software development project in Indonesia," J. Softw. Evol. Process, 2019.

[9] R. S. Dewi, G. F. Prassida, Sholiq, and A. P. Subriadi, "UCPabc as an integration model for software cost estimation," in Proceeding - 2016 2nd International Conference on Science in Information Technology, ICSITech 2016: Information Science for Green Society and Environment, 2017.

[10] P. Rijwani, S. Jain, and D. Santani, "Software Effort Estimation : A Comparison Based Perspective," Int. J. Appl. or Innov. Eng. Manag., 2014.

[11] K. Sangeetha and P. P. Dalal, “Analysis of Software Estimation Method: Function point and Use case point," vol, vol. 2, pp. 880-884, 2015. 
JURIKOM (Jurnal Riset Komputer), Vol. 7 No. 1, Februari 2020 e-ISSN 2715-7393 (Media Online), p-ISSN 2407-389X (Media Cetak) DOI 10.30865/jurikom.v7i1.1898

[12] O. Tailor, J. Saini, and M. P. Rijwani, "Comparative Analysis of Software Cost and Effort Estimation Methods: A Review," Interfaces (Providence)., vol. 5 , no. 7, p. $10,2014$.

[13] Sholiq, R. S. Dewi, and A. P. Subriadi, "A Comparative Study of Software Development Size Estimation Method: UCPabc vs Function Points," in Procedia Computer Science, 2017.

[14] R. S. Dewi, Sholiq, and A. P. Subriadi, "Game Complexity Factor: A Collaborative Study of LeBlanc Taxonomy and Function Points Method," in Proceedings of 2018 International Conference on Electrical Engineering and Computer Science, ICECOS 2018, 2019.

[15] R. S. Dewi, T. W. Andari, M. B. A. Rasyid, and R. Candra A.P., "Ekstraksi Faktor Kompleksitas Game Menggunakan Metode Function Points," J. Teknol. dan Sist. Inf., vol. 4, no. 3, pp. 115-122, 2018

[16] R. S. Dewi, T. W. Andari, A. P. Subriadi, and Sholiq, "Function Points Method in Game Casual Context," in Proceedings of 2018 International Conference on Electrical Engineering and Computer Science, ICECOS 2018, 2019. 